\title{
Management of an Infected Maxillary Periapical (Radicular) Cyst through Nasal Antrostomy
}

\author{
${ }^{1}$ Nalini MS, ${ }^{2}$ Balasubramanya Kumar, ${ }^{3}$ Sunil Shroff
}

\begin{abstract}
The radicular cyst is an inflammatory cyst that is formed as a consequence of pulpal necrosis mostly due to caries, which is often found and associated with periapical inflammation. Most of the times, radicular cysts resemble the preexisting chronic periapical periodontitis lesions radiographically. In this paper, a case of radicular cyst in the maxillary anterior region is discussed.
\end{abstract}

Keywords: Inflammatory cyst, Radicular cyst, Surgical enucleation.

How to cite this article: Nalini MS, Kumar B, Shroff S. Management of an Infected Maxillary Periapical (Radicular) Cyst through Nasal Antrostomy. J Health Sci Res 2016;7(2):58-62.

\section{Source of support: Nil}

Conflict of interest: None

\section{INTRODUCTION}

Cysts are pathological cavities filled with a fluid or semifluid contents and usually lined by epithelial tissue. Odontogenic cysts of the jaws are cysts in which the lining epithelium is derived from cells of the tooth forming tissues. With regards to the etiology of these lesions, they are traditionally classified into two main groups: developmental (dentigerous, keratocysts, gingival cysts, etc.) and inflammatory (radicular, residual, paradental cysts, etc.). ${ }^{1}$

Radicular cysts are the most common (52-68\%) cystic lesions affecting the jaws. They are most commonly found at the apices of the involved teeth; however, they may also be found on the lateral aspects of the roots in relation to lateral accessory root canals. ${ }^{2}$

Radicular cysts are direct sequel to chronic apical periodontitis but not every chronic lesion develops into a cyst. These cysts can occur in the periapical area of any teeth, at any age but are seldom seen associated with the primary dentition. ${ }^{1}$ It is more frequent in maxillary

\footnotetext{
${ }^{1}$ Reader, ${ }^{2}$ Head, ${ }^{3}$ Postgraduate Student

${ }^{1}$ Department of Periodontics, RajaRajeswari Dental College \& Hospital, Bengaluru, Karnataka, India

${ }^{2,3}$ Department of Dentistry and Maxillofacial Surgery, St. Martha's Hospital, Bengaluru, Karnataka, India

Corresponding Author: Nalini MS, Reader, Department of Periodontics, RajaRajeswari Dental College \& Hospital Bengaluru, Karnataka, India, Phone: +919986396654, e-mail: drnalinims79@gmail.com
}

than mandibular teeth. The radicular cyst is a chronic inflammatory lesion with a closed pathologic cavity lined either partially or completely by nonkeratinized stratified squamous epithelium. ${ }^{3-6}$ The underlying fibrous connective tissue wall is inflamed with varying degrees of cell infiltration, which consists mainly of macrophages and small blood vessels. ${ }^{5,7}$ Occasionally, however, radicular cysts are found to be lined, partially or predominantly, by columnar ciliated epithelium or mucosecretory cells, which may be due to the migration of these cells from either the maxillary sinus or the nasal cavity, the metaplasia of the stratified squamous epithelium, or to the differentiation of pluripotent cells within the jaw. ${ }^{8}$

Most of the radicular cyst do not show any clinical symptoms and are discovered only when periapical radiograph are taken of these nonvital teeth.

Patients often complain of slowly enlarging swellings. ${ }^{9}$ Radiographically, most radicular cyst appears as round or pear-shaped unilocular radiolucent lesion in the periapical region. The cyst may displace adjacent teeth or cause mild root resorption. ${ }^{10}$ The treatment options for radicular cyst can be conventional nonsurgical root canal therapy when lesion is localized or surgical treatment, like enucleation, marsupialization, or decompression, when lesion is large. ${ }^{11}$

This case report presents a successful surgical management of large infected radicular cyst.

\section{CASE REPORT}

A 44-year-old male patient reported to private clinic, with a chief complaint of slowly progressing swelling on the left side of the face of 4 to 5 years duration. Initially, it was soft and small in size, but gradually became larger and harder in consistency. Mild pain was experienced at times. The medical history was noncontributory. On examination, the patient was found to be a mediumstatured, averagely built, healthy male. A general survey of the patient did not reveal any abnormality of significance. Little facial asymmetry was observed due to swelling on the left side of the maxilla. The swelling was found approximately to be of $3.5 \times 3.5 \mathrm{~cm}$ in size and oval shaped (Fig. 1). The overlying skin showed normal color. The consistency of the swelling was bony hard. On palpation, it was mildly tender and there was no change 


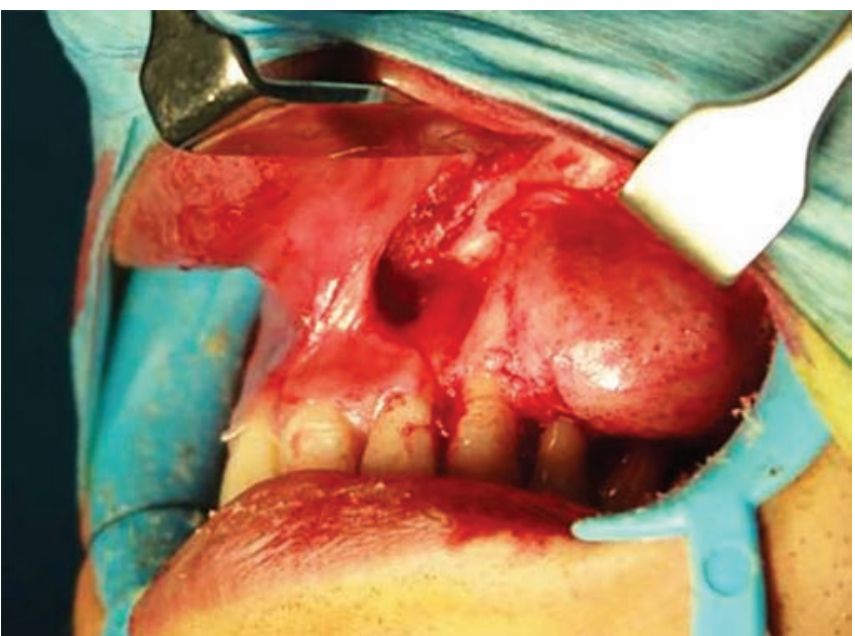

Fig. 1: Presurgical

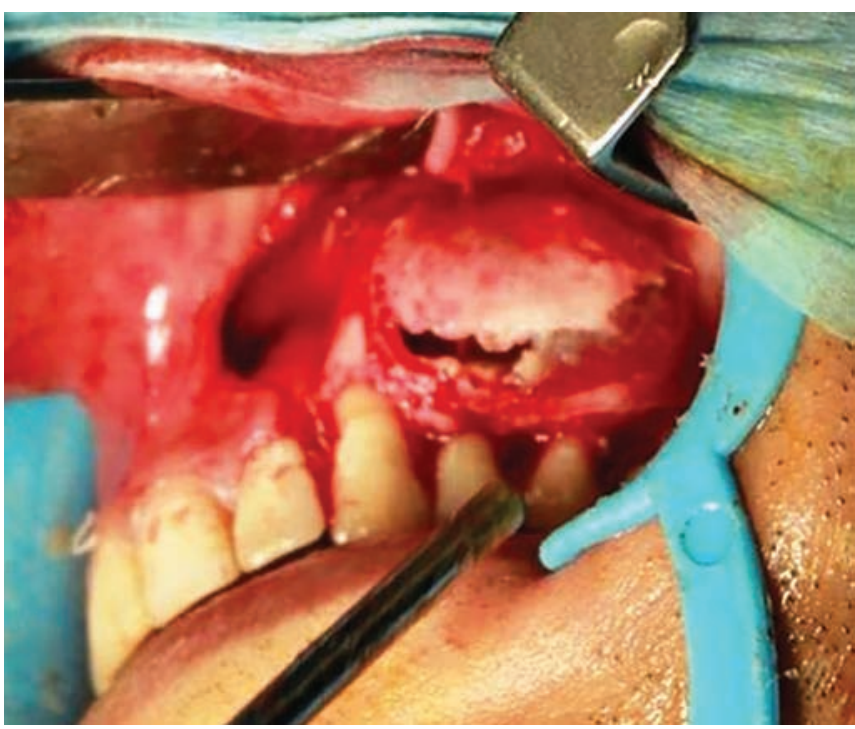

Fig. 3: Incision placement

in local temperature. The skin overlying the swelling was smooth, intact, and appeared little stretched. The detailed head and neck examination did not reveal any significant findings. Intraoral examination revealed there was a well-defined, localized swelling obliterating the buccal vestibule of left maxilla. The shape of the swelling was that of dome, soft, and fluctuant and was nontender on palpation. The overlying mucosa was smooth, little bit elevated, with no sign of clinical inflammation (Fig. 1).

After detailed analysis of history and clinical findings, a provisional diagnosis of a radicular cyst was made. Differential diagnosis were odontogenic keratocyst, cystic ameloblastoma, cystic degeneration of adenomatoid odontogenic tumor, and a cyst arising from the maxillary antrum. Swelling was in relation to left maxilla and the surrounding alveolar bone, so an intraoral radiographic examination was done. Radiographically, there was a unilocular radiolucency extending from the incisor-canine

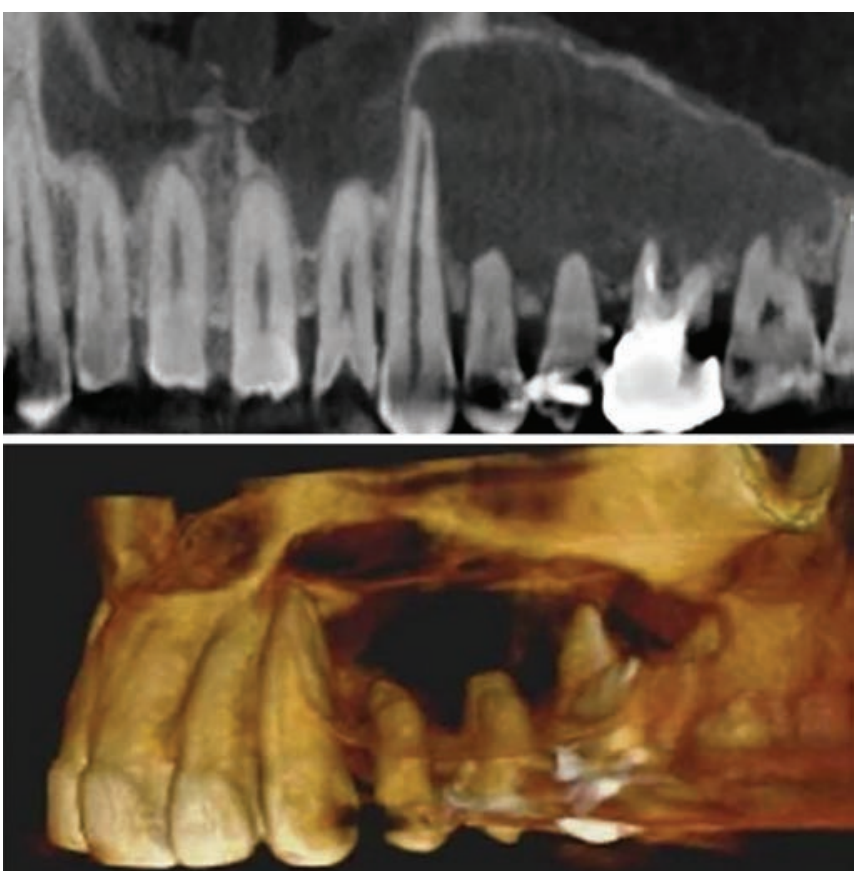

Fig. 2: Radiographic features

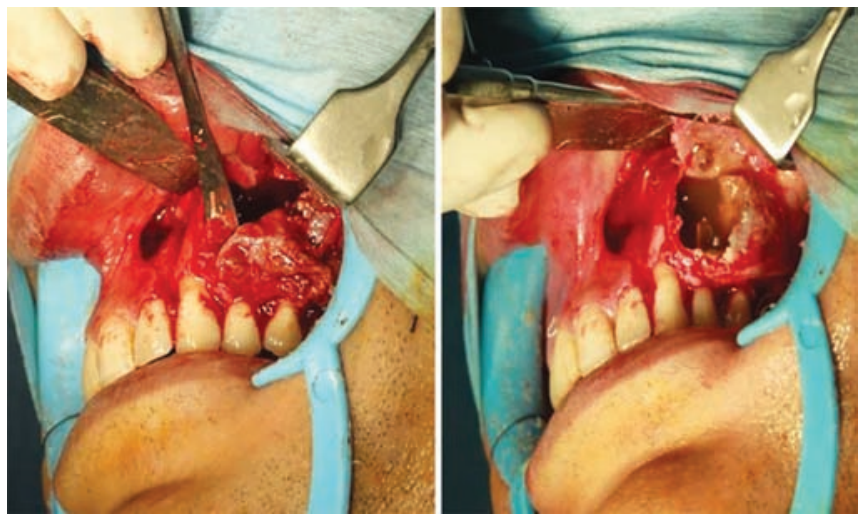

Fig. 4: Surgical enucleation

region to the third molar region in left maxilla. The lesion was seen extending into the nasal floor and the maxillary sinus with resorption of roots of premolars and thinning of the palatal bone. There was no evidence of root stump, cystic radiolucency, or any abnormality in relation to the floor of the maxillary sinus. The shape was oval, size was around $3 \times 2 \mathrm{~cm}$, and it extended anteroposteriorly from mesial of canine to mesial of third molar region. Superoinferiorly, it was not extended to displace teeth or floor of the orbit. The left zygomatic process, anterior wall, and floor of the maxillary sinus were not clearly demarcated, indicating lateral presence of the lesion causing displacement/resorption of these structures (Fig. 2).

The surgical enucleation of the cyst was carried out under general anesthesia and strict asepsis through an intraoral approach. A crevicular incision was placed buccally from incisor to molar region in left maxilla. A full thickness flap was raised to expose the wall of the cystic 


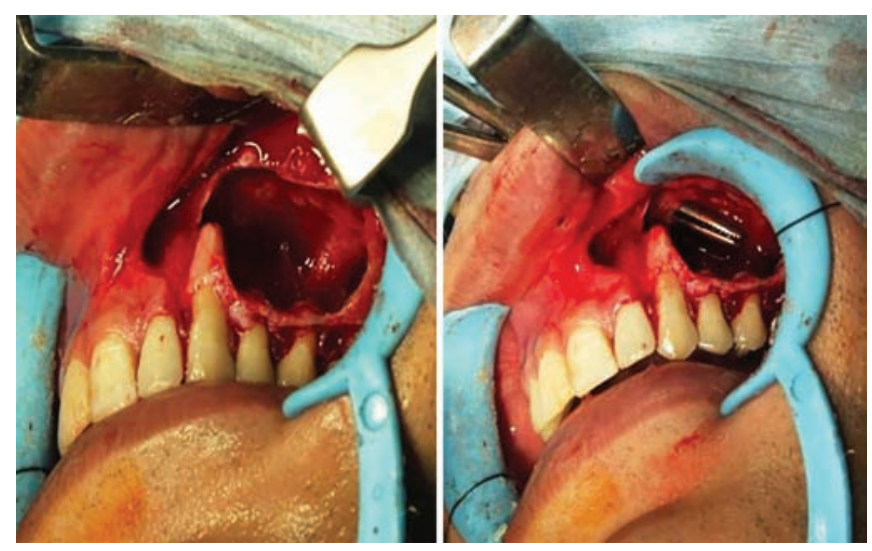

Fig. 5: The apical third of the roots of premolar and first molar was removed and burnished

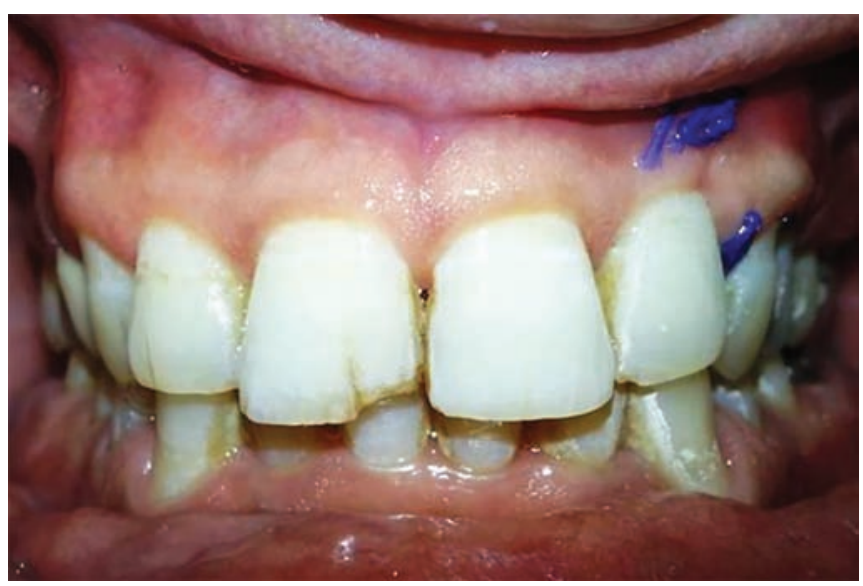

Fig. 7: Postsurgical healing

lesion (Fig. 3). The mucosa was carefully peeled of the wall of the lesion using fine dissectors and a knife. The lesion was then enucleated completely using blunt-ended elevators (Fig. 4). The apical third of the roots of premolar and first molar was removed and burnished (Fig. 5). An intranasal antrostomy was done followed by primary closure of the wound intraorally (Fig. 6). Postsurgical period was uneventful (Fig. 7). The specimen was sent for histopathological analysis (Fig. 8). The diagnosis of an established radicular cyst was confirmed when features of atrophic, metaplastic, nonkeratinized, stratified squamous epithelium with minimal inflammation were observed (Fig. 9).

\section{DISCUSSION}

The radicular cyst has been classified as inflammatory, because in the majority of cases it is a consequence of pulpal necrosis following caries, with an associated periapical inflammatory response. These cysts can occur in the periapical region of any teeth, at any age but seldom seen associated with the primary dentition. ${ }^{12}$ Few studies have shown that radicular cysts occur more commonly between the third to fifth decades of life, more common in males,

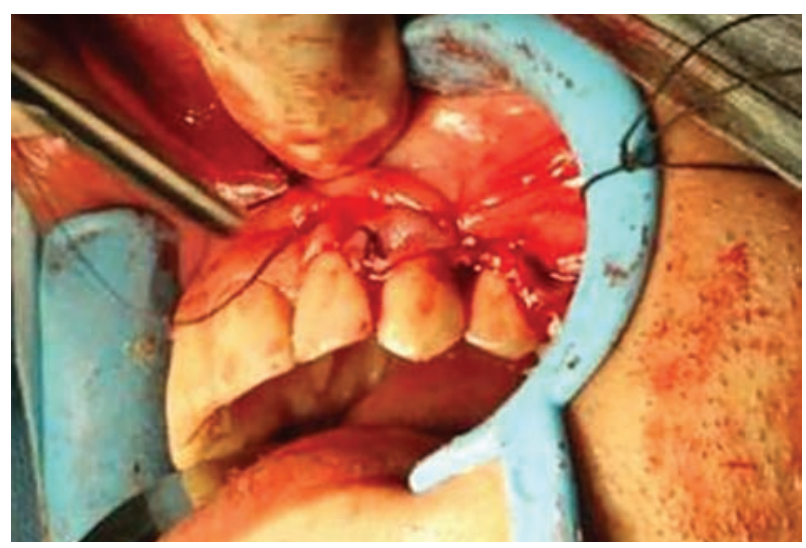

Fig. 6: Primary closure

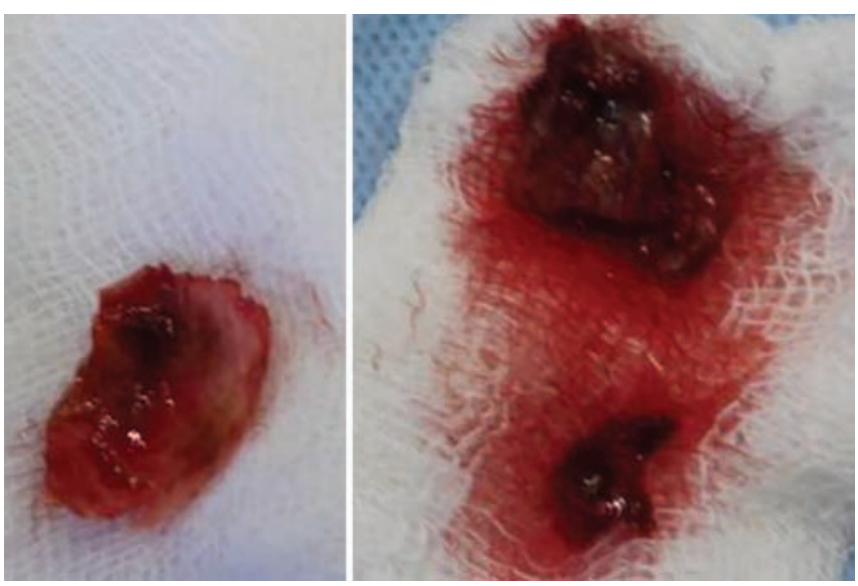

Fig. 8: Biopsy specimen

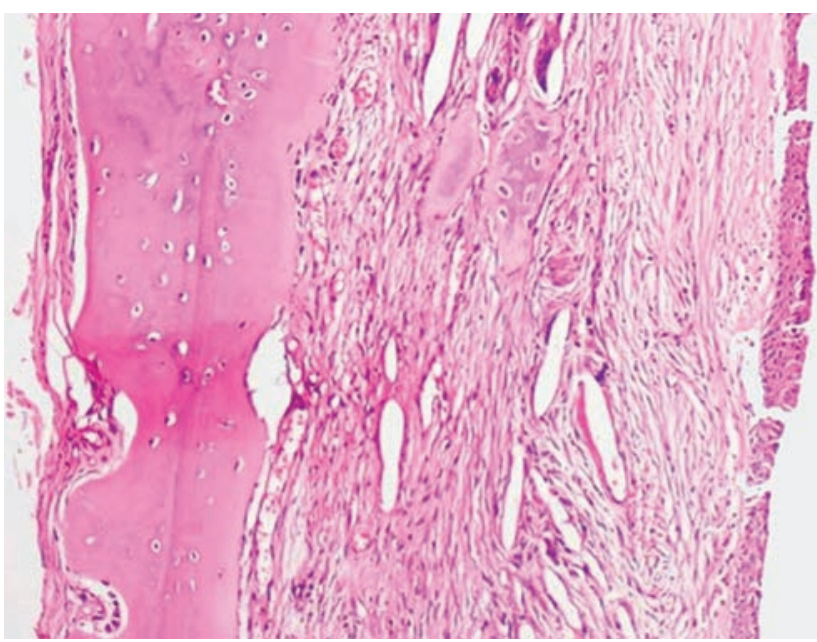

Fig. 9: Histological picture

about $58 \%$, than females, and more frequently found in the anterior maxilla than other parts of the mouth, about $60 \% .{ }^{13}$ It comprises $52.3 \%$ of all the cystic lesions of the jaw. Involvement of whites is about twice the frequency of blacks. They are found in association with nonvital teeth.

This case shows the above findings were seen in a male in the fourth decade with the lesion in the anterior region of his maxilla. 
The pathogenesis of radicular cysts has been described as comprising three distinct phases: The phase of initiation, the phase of cyst formation, and the phase of enlargement. ${ }^{14}$

Radicular cysts show no symptoms and are discovered when on viewing periapical radiographs of nonvital teeth. Patients often come with the complaint of slowly growing swellings. The enlargement is bony hard at first but with the increases in size of the cyst, the covering bone becomes very thin despite subperiosteal bone deposition and the swelling then exhibits "springiness." Fluctuation is seen only when the cyst has completely eroded the bone. In the maxilla there may be buccal or palatal enlargement whereas in the mandible it is usually labial or buccal and only rarely lingual. ${ }^{1}$ The other clinical features of radicular cysts include pain and infection. Radicular cysts are usually painless unless infected. Some patients with these lesions, however, complain of pain although no evidence of infection is found clinically and no evidence of acute inflammation is seen histologically after the cyst has been removed. Likewise, some patients have clinically infected and histologically inflamed cysts which are not painful. ${ }^{10,15}$ An important diagnosis criteria of a radicular cyst is the presence of nonvital pulp. At times, a sinus may be formed from the cyst cavity to the oral mucosa. ${ }^{1}$ Quite often, multiple radicular cysts may be present in a patient.

Radiographically, most radicular cysts appear as round or pear-shaped unilocular radiolucent lesions in the periapical region. The cysts may displace adjacent teeth or cause mild root resorption. Radiographically, distinguishing between a granuloma and a cyst is impossible, although some say that if the lesion is larger than $2 \mathrm{~cm}$ it is more likely to be a cyst. ${ }^{1,10}$

Microscopically, all radicular cysts are lined completely or partly by nonkeratinized stratified squamous epithelium. These linings may or may not be discontinuous and are 1 to 50 cell layers thick.

The inflammatory cell infiltrate in the proliferating epithelial linings consists predominantly of polymorphonuclear leucocytes, whereas the adjacent fibrous capsule is infiltrated mainly by chronic inflammatory cells. ${ }^{1}$ Approximately $10 \%$ of periapical cysts contain hyaline bodies in the epithelial linings and these bodies have a glassy pink (hyalinized) appearance. The origin of such bodies is believed to be related to previous hemorrhage within the inflamed cyst wall. ${ }^{1}$

Complications associated are as follows:

- Carcinomatous/neoplastic changes: Squamous cell carcinoma or epidermoid carcinoma may arise from epithelial lining of the cyst.

- Pathologic jaw fracture: If cyst is eroded completely especially in the posterior bone, which is very rare, it may cause pathologic bone fracture.
- Secondary infection: Secondary infection may occur in the cyst and may cause further complications.

The treatment of radicular cyst, as a disease of root canal infection, consists of eradicating microbes or substantially reducing the microbial load from the root canal and preventing reinfection by orthograde root filling. Prognosis of the treatment is remarkably good. In very rare cases, there are also factors located within the inflamed periapical tissue that can interfere with posttreatment healing of the lesion. ${ }^{2}$ Lesions that do not resolve with such therapy may be successfully managed by extraction of the associated nonvital teeth and curettage of the epithelium in the apical zone. Alternatively, a root canal filling may be performed in association with an apicoectomy to permit direct curettage of the cystic lesion. ${ }^{1}$

Other options are enucleation, marsupialization. Maxillary cysts can be treated through nasal antrostomy (Caldwell-Luc procedure), which was used in the current case study.

In the present case, as the patient was apprehended regarding the presence of a swelling and also the lesions size and extent, a surgical procedure was carried out. After endodontic therapy, complete enucleation of cyst and apicoectomy with retrograde filling with glass ionomer cement was done. Postsurgical period was uneventful. The cystic lesion was taken for histopathological examination. Histopathological features confirmed the clinical diagnosis of infected radicular cyst. The cystic cavity was lined by nonkeratinized stratified squamous epithelium and a mixed inflammatory infiltration was present. The choice of treatment may be decided by factors, such as the extension of the lesion, adjacent anatomic structures, evolution, origin, clinical characteristic of the lesion, cooperation, and systemic condition of the patient.

\section{CONCLUSION}

This clinical case was managed successfully by endodontic therapy followed by surgery. The treatment of the radicular cysts should be decided according to the clinical and radiographic evaluations according to each case.

\section{REFERENCES}

1. Shear, M. Radicular and residual cysts. In: Cysts of the oral region. 3rd ed. Bristol: Wright; 1992. p. 136-162.

2. Nair PNR. Non-microbial etiology: periapical cysts sustain post-treatment apical periodontitis. Endod Top 2003;6:96-113.

3. Nair PNR, Pajarola G, Schroeder HE. Types and incidence of human periapical lesions obtained with extracted teeth. Oral Surg Oral Med Oral Pathol Oral Radiol Endod 1996 Jan;81(1):93-102.

4. Nair PN, Sundqvist G, Sjögren U. Experimental evidence supports the abscess theory of development of radicular cysts. Oral Surg Oral Med Oral Pathol Oral Radiol Endod 2008 Aug;106(2):294-303. 
5. Kafas P, Dalfas S, Upile T, Jerjes W. Uncommon synchronous histopathological features of a radicular cyst: a case report. Cases J 2009 Aug;25(2):9067.

6. Neville, B.W.; Damm, D.D.; Allen, C.M.; Bouquet, J.E. In: Oral and maxillofacial pathology. 3rd ed. Saunders Elsevier; 2009. p. 130-131.

7. Tsai CH, Weng SF, Yang LC, Huang FM, Chen YJ, Chang YC. Immunohistochemical localization of tissue-type plasminogen activator and type I plasminogen activator inhibitor in radicular cysts. J Oral Pathol Med 2004 Mar;33(3):156-161.

8. García CC, Sempere FV, Diago MP, Bowen EM. The postendodontic periapical lesion: histologic and etiopathogenic aspects. Med Oral Patol Oral Cir Bucal 2007 Dec;12(8): E585-590.

9. Suhail L, Ajaz SA, Suhail JM. Radicular cyst: review. J Med Educ Res 2009;11:187-189.
10. Cawson, R.A.; Odell, E.W.; Porter, S. In: Cawson's essentials of oral pathology and oral medicine. 7th ed. Churchill Livingstone; 2002. p. 102-121.

11. Ribeiro PD, Gonçalves ES, Neto ES. Surgical approaches of extensive periapical cyst. Considerations about surgical technique. Salusvita Bauru 2004;23:317-328.

12. Grewal HK, Batra R. Non syndromic bilateral dentigerous cysts - A case report. Int J Dent Clin 2010;2(4):49-51.

13. Joshi N, Sujan S, Rachappa M. An unusual case report of bilateral mandibular radicular cysts. Contemp Clin Dent 2011 Jan-Mar;2(1):59-62.

14. Jansson L, Ehnevid H, Lindskog S, Blomlöf L. Development of periapical lesions. Swed Dent J 1993;17(3):85-93.

15. Bhaskar SN. Periapical lesion - Types, incidence and clinical features. Oral Surg Oral Med Oral Pathol 1966 May;21(5): 657-671. 